Available online at GSC Online Press Directory

GSC Biological and Pharmaceutical Sciences

e-ISSN: 2581-3250, CODEN (USA): GBPSC2

Journal homepage: https://www.gsconlinepress.com/journals/gscbps

(RESEARCH ARTICLE)

\title{
Evaluation of biochemical parameters and oxidative stress in native and crossbred cattle naturally infected with Dermatophytosis
}

\author{
Apaydin Yildirim Betul * \\ Ataturk University Veterinary Faculty, Department of Biochemistry, Erzurum, Turkey.
}

Publication history: Received on 04 November 2020; revised on 11 November 2020; accepted on 15 November 2020

Article DOI: https://doi.org/10.30574/gscbps.2020.13.2.0357

\begin{abstract}
Dermatophytosis is an endemic superficial zoonotic fungal infectious disease seen in many countries of the world affecting humans, cats, dogs, cattle, laboratory animals such as rabbits. T. verrucosum considered the main cause of ringworm in cattle. Cattle typically have circular, white-gray crust-shaped lesions on the skin on the neck and head. This study was carried out on a total of 40 native and crossbred cattle, 20 clinically healthy cattle and 20 clinical cases of dermatophytosis. The influence of dermatophytosis on lipid peroxidation and the antioxidant system was investigated. Serum MDA, TAS, TOS, GSH, GPx, SOD and CAT level were measured in groups. Cattle in group dermatophytosis had significantly higher MDA and TOS level and TAS, GSH levels, GPx, SOD and CAT activities were significantly lower (P < 0.001). These findings suggest a relationship between dermatophytosis, the oxidant-antioxidant system and lipid peroxidation.
\end{abstract}

Keywords: Dermatophytosis; MDA; Oxidative stress; Cattle; Serum

\section{Introduction}

Dermatophytosis, Tinea or Ringworm, is a superficial fungal infection of mainly hair, skin and other tissues, hair removal, folliculitis, exudation and other clinical signs which is an infection of domestic animals as well as human caused by various fungi, including Epidermophyton spp., Trichophyton spp. and Microsporum spp. The disease as a major public health problem is widespread and economically important. Following infection, the skin response after infection varies from mild to severe, depending on various factors such as host reaction to the metabolic products of the fungus, anatomical location and environmental factors, virulence of the infecting fungus, the infected site (location), and host response.

Following infection, skin response is mild to severe, depending on various factors, such as the hosts reaction to the metabolic products of the fungus, virulence of the infecting fungus, anatomic location, and environmental factors. Crowded housing, as is seen in winter housing, increases the incidence of the disease is also hot and humidity climate [1-4].

Dermatophytosis has adverse effects on animal growth, skin integrity and meat production. For this reason, these diseases should be prevented and controlled since they can cause great economic losses in livestock. The infection caused by Microsporum gypseum, Trichophyton verrucosum (T. verrucosum), Trichophyton mentagrophytes, Trichophyton rubrum and Trichophyton simii has been reported [5].

\footnotetext{
* Corresponding author: Apaydin Yildirim Betul

Ataturk University Veterinary Faculty, Department of Biochemistry, Erzurum, Turkey.. 
Increased free radicals in cells cause oxidative stress due to imbalance of oxidant and antioxidant factors. [6]. It is very important to find biomarkers occurring in oxidative stress for risk stratification and prognosis evaluation in the disease. Generally, the overall antioxidant status of the body is determined to measure the the total antioxidant status (TAS), and to assess the oxidation state, the total oxidant status (TOS). In addition, the oxidative stress index (OSI), the ratio of TOS to TAS, is calculated as a more precise biomarker reflecting oxidative stress and may reflect the imbalance between antioxidants and oxidation [7-9]. Malondialdehyde (MDA) is the indicator of oxidative stress and the end product of lipid peroxidation. Glutathione peroxidase (GPx), superoxide dismutase (SOD) and catalase (CAT) are some of the important antioxidant enzymes. In the absence of these antioxidant enzymes, lipid peroxidation occurs in cell membranes.

The effector mechanisms required to kill the causative agents of in dermatophytosis are not fully understood [11]. It is seen that the biochemical changes of dermatophytosis in cattle, especially oxidative stress and antioxidant enzymes have not been sufficiently studied. Therefore, the aim of this study was to determine the levels of TAS, TOS, OSI, MDA, GSH; GPx, SOD and CAT activities in native and crossbred cattle with Dermatophytosis.

\section{Material and methods}

\subsection{Animals and experimental design}

During a routine veterinary examination of cattle at a farm located in Erzurum region, a total of 40 cattle clinical signs of dermatophytosis were noted in age from 8 to 18 months, native and crossbred cattle. The ethical norms were obtained prior to start study for Science Ethics Committee Decision (No: 06.04.2018 -ATA-46 Turkey/Erzurum). The animals were divided into two groups, namely, control (non-infected, healthy) group ( $\mathrm{n}=20)$ and dermatophytosis (infected) group $(n=20)$, which were found to have dermatophytosis in mycological examinations of samples taken under appropriate conditions and showing all clinical signs of dermatophytosis according to clinical examinations. Calves lesions are mainly on head and neck, few lesions were seen on the trunk and back. Round areas of alopecia with a diameter of $0.5-2 \mathrm{~cm}$ in various places, mainly on the head and body, were covered with thick scales (Figure 1). Diseased and healthy cattle were kept in different barns on the same farm. All calves in both groups were subjected to similar management conditions.

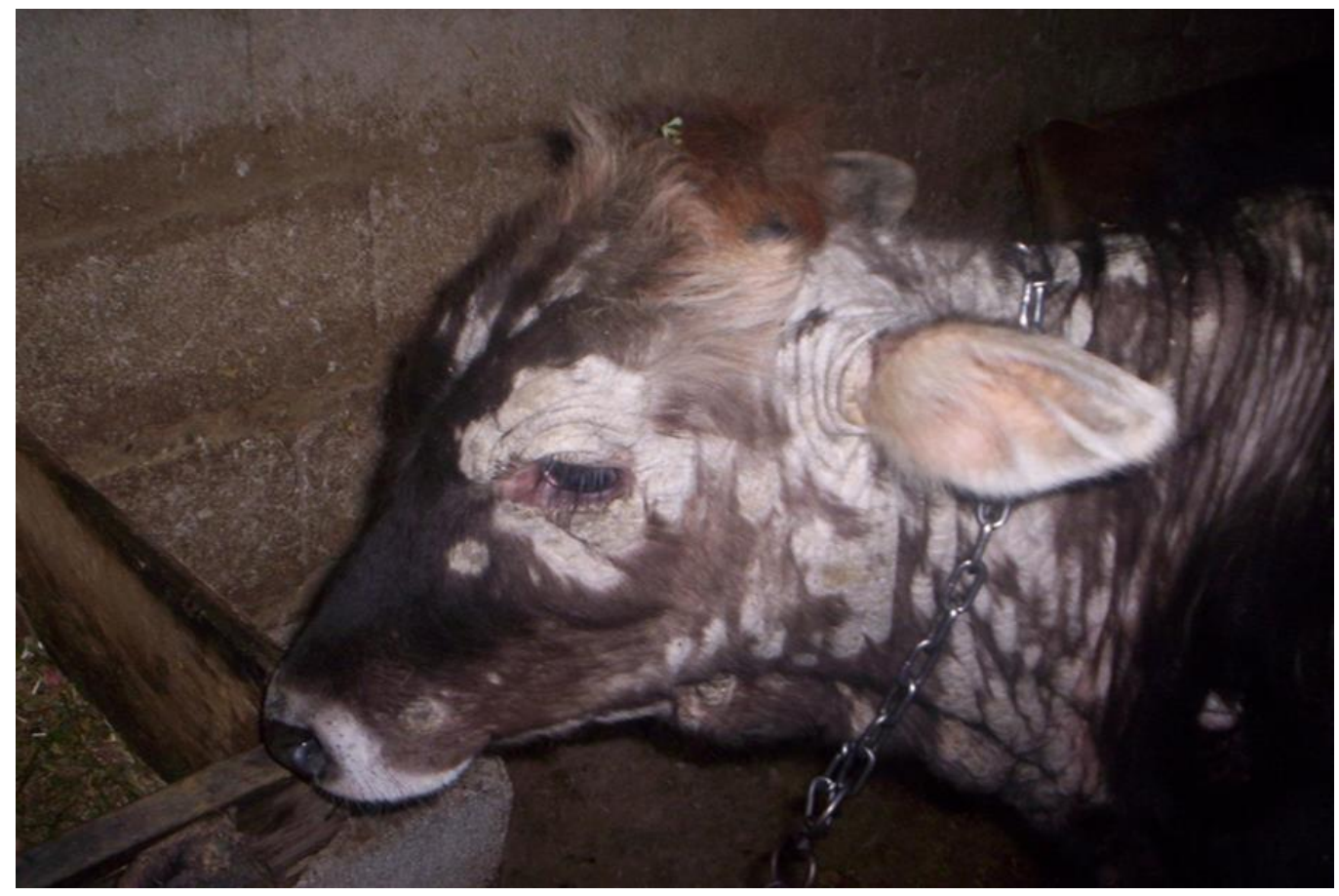

Figure 1 Dermatophytosis in native and crossbred cattle. Multifocal dermatophytosis lesions that appear as dry, crusted areas of alopecia grayish-white desquamations around the head and neck in a native and crossbred cattle.

\subsection{Mycological examination}


Hair samples and skin scraping were collected from the periphery of the lesions signs of dermatophytosis after wiping with sterile cotton dipped in 70\% ethyl alcohol. After the alcohol was dried, sufficient amount of skin scrapings and hair samples were collected from the active areas at the margin of the lesions by scraping with a scalpel in sterile falcon tubes and sent for fungal examination at laboratory (YYU, Department of Microbiology, Turkey). By adding $10 \% \mathrm{KOH}$ solution to the samples taken, hyphae, macroconidium, microconidium, blastospore, arthrospores and chlamidospore structures of dermatophytes were searched in direct microscopic examination. Separately, the cultures were inoculated onto into Sabouraud Dextrose Agar (SDA) by horizontal stub method and incubated at $37{ }^{\circ} \mathrm{C}$ for 21 days. The species of dermatophyte were identified based on production of typical spores and colony texture. The growth status and duration, shape, structure and pigmentation characteristics on the anterior and posterior surfaces of the colonies formed macroscopically in the medium were taken into consideration. In the morphological examination of urinary colonies by microscope; It was identified by staining with lactophenol solution by looking at the colonies' hyphae, microconidium, macroconidium, chlamidospore, arthrospore and blastospore structures. It was determined that the samples taken were T. verrucosum after isolation and identification procedures.

\subsection{Biochemical analysis}

Blood samples were taken according to the procedures from $V$. jugularis. Whole blood was collected into serum separating tubes (without anticoagulants). Serum was obtained from these whole blood samples by centrifugation ( $4000 \mathrm{rpm}$ for $10 \mathrm{~min}$ ) to separate the serum and stored at $-20^{\circ} \mathrm{C}$ for estimating the levels of Total oxidant status (TOS) and Total antioxidant status (TAS) levels by quantitative enzyme linked immunosorbent assay kits (Rel Assay Diagnostics Kit) according to the manufacturer's instructions. TAS results are expressed in mmol Trolox Equ./L. TOS results were expressed as $\mu \mathrm{mol} \mathrm{H} 202 \mathrm{Equ} / \mathrm{L}$. For the calculation of Oxidative stress index (OSI), TAS unit was converted to $\mathrm{mmol} \mu \mathrm{mol}$ unit and OSI results were expressed as "arbitrary unit" (AU) and calculated by the following formula.

OSI = (TOS, $\mu$ mol H2O2 Equ./ L / TAS, mmol Trolox Equ ./ L) X 100

The total protein amount was measured according to the method of Lowry et al [12]. The levels of MDA [13], GSH [14]; GSH-Px [15], SOD [16] and CAT activities [17] from the serums obtained were measured using a spectrophotometer (Biotek ELISA Reader model $\mu$ Quant MQX200 /USA) in accordance with the procedure.

\subsection{Statistical analysis}

Independent $t$ test was used for statistical analysis using SPSS software package, 22.0 version. Datas are expressed as mean \pm standard error

\section{Results}

Presented in Table 1 are levels of TAS, TOS, OSI, concentrations of lipid peroxidation product (MDA), GSH levels, GPx, SOD and CAT activities in the control and dermatophytosis groups. The results were presented as mean \pm standard error (mean \pm SEM) $(\mathrm{P}<0.001)$ for 20 cattle in each group.

Table 1 Serum biochemical parameter of cattle infected with T. verrucosum and healthy cattle.

\begin{tabular}{|l|l|l|}
\hline Groups & Control Group & Dermatophytosis Group \\
\hline TAS (mmol Trolox Equ./L) & $2.48 \pm 0.01$ & $1.16 \pm 0.01$ \\
\hline TOS ( $\mu \mathrm{mol} \mathrm{H}_{2} \mathrm{O}_{2}$ Equ./L) & $6.06 \pm 0.24$ & $12.06 \pm 0.58$ \\
\hline OSI $(\mathrm{AU})$ & $0.24 \pm 0.01$ & $1.04 \pm 0.05$ \\
\hline $\mathrm{MDA}(\mathrm{mmol} / \mathrm{L})$ & $6.35 \pm 0.06$ & $23.32 \pm 0.44$ \\
\hline GSH $(\mathrm{nmol} / \mathrm{L})$ & $0.67 \pm 0.01$ & $0.30 \pm 0.00$ \\
\hline $\mathrm{GPx}(\mathrm{U} / \mathrm{mL})$ & $0.24 \pm 0.00$ & $0.12 \pm 0.01$ \\
\hline SOD $(\mathrm{U} / \mathrm{mL})$ & $3.41 \pm 0.06$ & $1.49 \pm 0.06$ \\
\hline $\mathrm{CAT}(\mathrm{KU} / \mathrm{L})$ & $35.11 \pm 0.49$ & $21.76 \pm 0.20$ \\
\hline $\mathrm{P}$ & 0.000 & 0.000 \\
\hline
\end{tabular}


Serum TOS, OSI and MDA level in control group was determined as 6.06 $\pm 0.24 \mu \mathrm{mol} \mathrm{H2O2} \mathrm{Equ./L,} \mathrm{while} \mathrm{serum} \mathrm{OSI} \mathrm{level}$ was $0.24 \pm 0.01 \mathrm{AU}$ and MDA level was $6.35 \pm 0.06 \mathrm{mmol} / \mathrm{L}$. As shown in Table 1, serum TOS, OSI and MDA level in dermatophytosis group was determined as $12.06 \pm 0.58 \mu \mathrm{mol} \mathrm{H} 202 \mathrm{Equ} . / \mathrm{L}, 1.04 \pm 0.05 \mathrm{AU}$ and $23.32 \pm 0.44 \mathrm{mmol} / \mathrm{L}$ which was significantly higher than control group $(\mathrm{P}=0.000)$. TAS, the level of GSH which is a nonenzymatic antioxidant, the activity of the antioxidant enzymes GPX, SOD and CAT were significantly decreased in dermatophytosis group when compared to control group ( $\mathrm{p}<0.001)$.

\section{Discussion}

According to clinical signs and research results, dermatophyt lesions can be seen mainly on the head and neck, especially around the eyes and face, and even on the whole body. The reason why it is seen especially in the head and neck has not been clarified yet. Since the skin tissue around the eyes of cattle is soft, it is more sensitive to the adhesion and growth of the fungus.

In the case of oxidative stress, there is insufficient antioxidant capacity that causes excessive production of free radicals that damage cellular compounds such as DNA, Proteins and lipids by accumulating end products of lipid peroxidation such as MDA [18]. The importance of oxidative stress and oxidative stress parameters, which are defined as the disruption of the balance between antioxidants and oxidants, in determining the prognosis, pathogenesis or etiology of various diseases in farm animals is known [19]. Antioxidant oxidant balance changes in many infected diseases such as parasitic , bacterial and fungal diseases. Some authors reported antioxidant oxidant imbalance in infected animals with dermatophytosis $[20,21]$. Formation of free radicals and subsequent lipid peroxidation may be caused by dermatophytosis through the production of ROS following skin damage [22]. Natural defenses against dermatophytes depend on non-immunological and immunological mechanisms [23]. Although some systemic fungi have antioxidant systems, there is no such information about dermatophytosis in the published work [24]. For this reason, we do not know whether the skin or host is the principle source of increased antioxidant enzymes. In the present study, we have found a significant increase in TOS, OSI and MDA levels and decrease in TAS, GSH levels, GSH-Px, SOD and CAT activities in the serum of dermatophytosis cattle compared to control cattle. This is in agreement with dermatophytosis animal studies [25-28].

\section{Conclusion}

Our results suggest a possible relationship between antioxidant imbalance, lipid peroxidation, and dermatophytosis disease; however, in order to more definitively delineate the pathogenesis of dermatophyte infection, further studies are necessary. The determination of oxidative stress may require that clinicians treating this disease should include antioxidative drugs together with antifungal agents treatment regime.

\section{Compliance with ethical standards}

\section{Acknowledgments}

The authors are thankful to Department of Microbiology, YYU for the laboratory facilities provided.

\section{Disclosure of conflict of interest}

Betul Apaydin Yildirim declare that there is no conflict of interest in the present study.

\section{Statement of ethical approval}

The ethical norms were obtained prior to start study for Science Ethics Committee Decision (No: 06.04.2018 -ATA-46 Turkey/Erzurum).

\section{References}

[1] Diongue K, Bréchard L, Seck, Diallo AM, Seck MC, Ndiaye M, Badiane AS, Ranque S, Ndiaye D. A Comparative Study on Phenotypic versus ITS-Based Molecular Identification of Dermatophytes Isolated in Dakar, Senegal. Int J of Microbiol. 2019; 1-6.

[2] Guo Y, Ge S, Luo H, Rehman A, Li Y, He S. Occurrence of Trichophyton verrucosum in cattle in the Ningxia Hui autonomous region, China. BMC Veterinary Research. 2020; 16(1): 1-9. 
[3] Papini R, Nardoni S, Fanelli A, Mancianti F. High infection rate of trichophyton verrucosum in calves from Central Italy. Zoonoses Public Hlth. 2010; 56: 59-64.

[4] Agnetti F, Righi C, Scoccia E, Felici A, Crotti S, Moretta L, Moretti A, Maresca C, Troiani L, Papini M. Trichophyton verrucosum infection in cattle farms of Umbria (Central Italy) and transmission to humans. Mycoses. 2014; 57: 400-5.

[5] Hameed K, Riaz CF, Nawaz MA, Sms N, Grãser Y, Kupsch C. Trichophyton verrucosum infection in livestock in the chitral district of Pakistan. J Infect Dev Ctries. 2017; 11: 326-33.

[6] Davies RR Zaini F. Trichophyton rubrum and chemotaxis of poly-morphonuclear leukocytes. J Med Vet Mycol. 1984; 22: 65.

[7] Harma M, Harma M, Erel O. Increased oxidative stress in patients with hydatidiform mole. Swiss Med Wkly. 2003; 133(41-42): 563-566.

[8] Erel 0. A novel automated direct measurement method for total antioxidant capacity using a new generation, more stable ABTS radical cation. Clin Biochem. 2004; 37(4): 277-285.

[9] Erel O. A new automated colorimetric method for measuring total oxidant status. Clin Biochem. 2005; 38(12): 1103-1111.

[10] Sarici G, Cinar S, Armutcu F, Altinyazar C, Koca R, Tekin NS. Oxidative stress in acne vulgaris. J Eur Acad Dermatol Venereol. 2011; 24: 763-767.

[11] Calderon RA, Hay RJ. Fungicidal activity of human neutrophils andmonocytes on dermatophytic fungi, Trich ophyton quinckeanum and Trichophyton rubrum. Immunology. 1987; 61: 289-295.

[12] Lowry OH, Rosebrough NJ, Farr AL, Randall RJ. Protein measurement with the Folin phenol reagent. J Biol Chem. 1951; 193(1): 265-275.

[13] Yoshioka T, Kawada K, Shimada T. Lipid peroxidation in materyal and cord blood and prodective mechanism against activated-oxygen toxicity in the blood. Am J Obstet Gynecol. 1979; 135(3): 372-376.

[14] Tietze F. Enzymic method for quantitavite determination of nanogram amounts of total and oxidized glutathione. Anal Biochem. 1969; 27(3): 502-522.

[15] Matkovics B. Determination of enzyme activities in lipid peroxidation and glutathione pathways. Laboratoriumi Diagnosztika. 1988; 15: 248-249.

[16] Sun Y, Oberley LW, Li Y. A simple method for clinical assay of superoxide dismutase. Clin Chem. 1988; 34(3): 497500 .

[17] Goth L. A simple method for determenation of serum catalase activity and revision of serum catalase activity and revision of reference range. Clin Chim Acta. 1991; 196(2-3): 143-152.

[18] Halliwell B. Antioxidant defense mechanisms: from the beginning to the end of beginning. Free Radic Res. 1999; 31: 261-272.

[19] Yurdakul İ, Apaydin Yildirim B. Yeni doğan buzağıların artrit, intestinal atresia, kırık ve omphalit olgularında toplam antioksidan kapasite, toplam oksidan durum ve malondialdehit seviyelerinin değerlendirilmesi. 4. Uluslararası Bilimsel Araştırmalar Kongresi, Yalova. 2019; 65-70.

[20] Van de Crommenacker J, Richardson DS, Koltz AM, Hutchings K, Komdeur J. Parasitic infection and oxidativestatus are associated and vary with breeding activity in the Sey-chelles warbler. Proc Biol Sci. 2012; 279 (1733): 1466-1476.

[21] Jain R, Dey B, Khera A, Srivastav P, Gupta UD, KatochVM, Tyagi AK. Over-expression of superoxide dismu-tase obliterates the protective effect of BCG against tuberculosis bymodulating innate and adaptive immune responses. Vaccine. 2011; 29(45): 8118-8125.

[22] Koca R, Armutcu F, Altinyazar HC, Gurel A. Oxidant- antioxidant enzymes and lipid peroxidation in generalized vitiligo. Clin Exp Dermatol. 2004; 29: 406-409.

[23] Tainwala R, Sharma YK. Pathogenesis of dermatophytoses. IndianJ Dermatol. 2011; 56: 259-262.

[24] Dantas AS, Andrade RV, De Carvalho MJ, Felipe MSS Campos EG. Oxidative stress response in Paracoccidioides brasiliensis: assessingcatalase and cytochrome c peroxidase. Mycol Research. 2008; 112: 747-756. 
[25] Lee SH, Park BY, Lee SS, Choi NJ, Lee JH, Yeo JM, Ha JK, Maeng WJ, Kim WY. Effect of spent composts of seleniumenriched mushrooms on carcass characteristics, plasma glutathione peroxidase activity, and selenium deposition in finishing Hanwoo steers. Asian-Aust J Anim Sci. 2006; 19: 984-991.

[26] Karapehlivan M, Uzlu E, Kaya N, Kankavi O. Investigation of some biochemical parameters and the antioxidant system in calves with dermatophytosis. Turk J Vet Anim Sci. 2007; 31(1): 1-5.

[27] Al-Qudah KM, Gharaibeh AA, Al-Shyyab MM. Trace minerals statusand antioxidant enzymes activities in calves with dermatophytosis. Biol Trace Elem Res. 2010; 136: 40-47.

[28] Yildirim M, Cinar M, Ocal N, Yagci BB, Askar S. Prevalence of clinical dermatophytosis and oxidative stress in cattle. J Anim Vet Adv. 2010; 9: 1978-1982. 